\title{
La Salud Publica, herramienta de las Ciencias Veterinarias para la Sociedad
}

Iniciando el tercer milenio, surgieron inquietudes en las instituciones mundiales de la salud para idear $y$ estudiar la viabilidad de crear una campaña para la prevención y el tratamiento de enfermedades humanas y animales, proponiendo el concepto integrador de Una Sola Salud, siempre enmarcando las dimensiones ecológica y ambiental. Para ello, se necesitaba el trabajo mancomunado de todos los sectores involucrados, profesionales, asociaciones, instituciones, sector productivo, universidades, entre otras; con la finalidad de abordar las complejas adversidades sanitarias mediante un enfoque holístico abarcando el bienestar animal, de seres humanos y de los ecosistemas que ellos habitan. Este nuevo paradigma sanitario mundial reconoce que la salud humana está estrechamente relacionada con la salud de los animales y el ambiente, concibiendo los esfuerzos transdisciplinarios para lograr una salud óptima en los mismos.

Actualmente, La Organización Mundial de la Salud (OMS), la Organización de las Naciones Unidas para la Agricultura y la Alimentación (FAO), la Organización Mundial de Sanidad Animal (OIE), los Centros para el Control de Enfermedades (CDC) y la Unión Europea apoyan la adopción del Enfoque de salud para aumentar la resiliencia de los sistemas sanitarios, tanto a nivel nacional como internacional y responder a las enfermedades infecciosas emergentes y los brotes, mediante una alianza formal concertada. Todas estas sinergias entre especialistas de la salud animal, de la salud pública y del ambiente contribuyen a la mejora continua y simultánea de la salud pública y de la salud animal en el mundo.

Factores como el crecimiento poblacional, la globalización del comercio, la vulnerabilidad económica, la intensificación de la producción pecuaria y agrícola, el cambio climático y la deforestación, el tránsito cada vez mayor de personas, animales, plantas y alimentos, aunado a los efectos devastadores de la pandemia de la COVID-19, han alterado las interacciones entre los seres humanos, los animales y el ambiente. Estos cambios han dificultado o entorpecido aún más a la prevención, el manejo y la erradicación de enfermedades infecciosas, tales como la rabia, los virus zoonóticos de la influenza, brucelosis y encefalopatías espongiformes bovina, así como también la inducción de resistencia a los antimicrobianos; lo cual han provocado la aparición y reaparición de muchas enfermedades emergentes y reemergentes, conllevando a graves problemas de salud pública.

La Facultad de Ciencias Veterinarias de La Universidad del Zulia, enfrenta de esta manera la necesidad de replantear sus paradigmas con respecto al perfil del veterinario del futuro. Este nuevo escenario demandará un veterinario formado de manera integral con bases científicas profundas, capaz de analizar problemas que trasciendan más allá de la resolución del caso clínico. Su gran fortaleza se centra en una gran herramienta académica, la Revista Científica, renovada, actualizada y siempre soportada por su exitoso recorrido histórico, brindando información científica valiosa a todo el mundo, gracias a los aportes investigativos nacionales e internacionales. Dentro de su contenido veterinario, tiene al alcance una de las áreas con implicancia en lo antes discutido "la salud pública vinculada a las ciencias veterinarias (zoonosis)", donde existe la oportunidad de recibir y publicar artículos científicos que aborden el enfoque "Una Salud" como una estrategia para diseñar e implementar prácticas, programas, políticas, legislación e investigación, con el fin de lograr mejores resultados en Salud Pública.

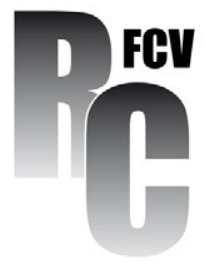

Profesor MSc. Julio César Boscán Ocando

Director de División de Extensión 